\title{
THE IMPACT OF ANTHROPOGENIC ALLUVIAL ARRAYS ON AREAS SETTLEMENTS DEPENDING ON THE PARTICLE SIZE DISTRIBUTION OF STORED TAILLINGS
}

\author{
Andrey Vladimirovich Ivanov' ${ }^{1}$ Yuri Dmitrievich Smirnov ${ }^{1}$ \\ 1 National Mineral Resources University (Mining University), 21st Line of Vasilyevsky Island, Saint-Petersburg, \\ 199106, Russia, e-mail: andrey-racer@mail.ru, qwerik84@gmail.com
}

Received: 2015.12 .14

Accepted: 2016.03.04

Published: 2016.04.01

\begin{abstract}
Developing devices for dust suppression one should consider important factors, such as the size distribution of transferred dust, duration of exposure in residential areas. Often the total amount of dust emissions may exceed the estimated figure for maximum permissible emissions, but their share transferred in sanitary protection zone of dust is negligible. Tailing dump of Kovdor MPE is one of the largest in Russia. The construction of dust dispersion halos was performed using a universal program calculation of air pollution "Ecolog" (Russia). Based on a comparison of dispersed compositions tails similar in composition tailing dumps in Russia, it can be concluded that in the beach area of the Kovdor dump share of dust tranfered to the territory of settlements has ranged from 10 to $40 \%$. It was found that the maximum diameter of the particles carried by the territory of the city under consideration is 50 microns. We can conclude that under the conditions of the object the development of special devices for dust suppression is required.
\end{abstract}

Keywords: dust, tailings, dump, humidity, dust transfer, dust suppression, pulp.

\section{INTRODUCTION}

Tailings is a set of special facilities and equipment intended for storage or disposal of mineral processing (including toxic and radioactive), called tailings. In the mining and processing complex from entering mined ore concentrate obtained and the solid-liquid processing waste is moved to the tailing dumps. Typically tailings construct a few kilometers from the ore processing factory in depressions (hollows, gorges). From contaminant dam is filled, which encloses the tailing dump. There is a defending division into sedimentary solid phase tailings and water. The water is used for the second ore processing factory or cleaned and discharged into drains. On the terrain of the tailings are divided into: featureless, ravine, floodplain, quarry, mine, mountainous. The accumulated technological waste is a potential large-raw materials. Made without regard to filtering and other factors old tailing dumps are often a source of environmental hazards, including pollution source groundwater and atmosphere [Kozlowsky 1991].

\section{MATERIAL AND METHODS}

The work was carried out on the material and technical base of the Center of Collective Use and Training of the experimental workshop of the Mining University. The shared center combines a unique set of instruments and software that allows to solve a wide range of scientific problems.

The main research methods used included:

- system-structural analysis of production facilities contributors to the deterioration of the dusty environment;

- analytical and experimental work in the laboratory and field conditions;

- methods of mathematical modeling of dust transfer to the factory's facilities. 
The analysis of the impact of technogenic alluvial arrays produced by the example of the company "Kovdor Mining and Processing Enterprise" (Kordor MPE) (northwest Russia) is engaged in mining of iron ore, extraction and processing of apatite.

\section{RESULTS AND DISCUSSIONS}

Tailing dump of Kovdor MPE is one of the largest in Russia. The operation of the enterprise is the cause of the deterioration of the dusty environment in the town of Kovdor and contributes significantly to the cross-border transfer in the protected areas of Finland. Its area of $7 \mathrm{~km}^{2}$. Tailings formed by natural hill from the southwestern, southern and south-eastern side and the bulk dam on the north and north-western side of $55 \mathrm{~m}$ height difference relative to the location of Kovdor and the village of Severnoe Siyanye. On the southern part of the tailing five streams run, which helps to maintain the irrigation of the area $\left(\sim 2.1 \mathrm{~km}^{2}\right)$, and leads to a reduction of possible dusting area. On tailing alluvium carried alter- nately out of 16 issues of the pulp along the dam that keeps the largest area beaches wet.

However, under adverse weather conditions in the air of residential areas there is an excess of maximum permissible concentration of the silicon dust up to 5 ones of maximum permissible concentration (Figure 1). The construction of dust dispersion halos in Figure 1 is performed using a universal program calculation of air pollution "Ecolog" version 3.0. (Russia). The program does not take into account wind direction and carries out calculations using the parameter sedimentation coefficient, which is accepted for all fractions of dust 2.5. However, actually, small fraction of dust can have lower sedimentation coefficients. Currently, the length of dusty tailings beaches is $4600 \mathrm{~m}$ with an average width of $150 \mathrm{~m}$. There is a perspective of increasing the area of dusty beach as a result of the restructuring of the tailing dump.

Size distribution of the sample of tailings beach area of Kovdor MPE dump, determined using Particle Analyzer HORIBA LA 950 Division analyzes CCU Mining University, as presented in Figure 2.

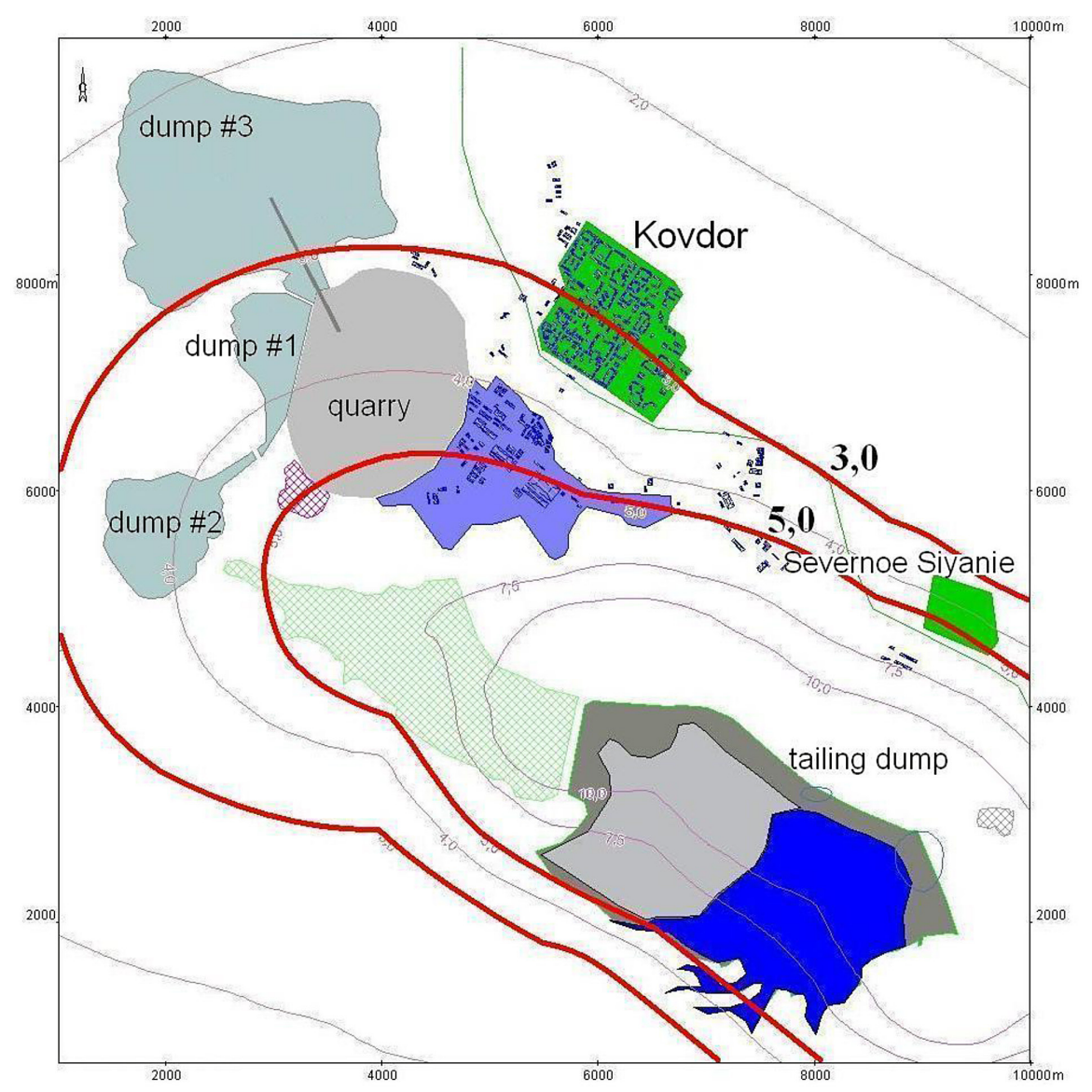

Figure 1. Halos dispersion of inorganic dust from tailings enterprise Kovdor MPE, created with using the software package "Ecolog" version 3.0 


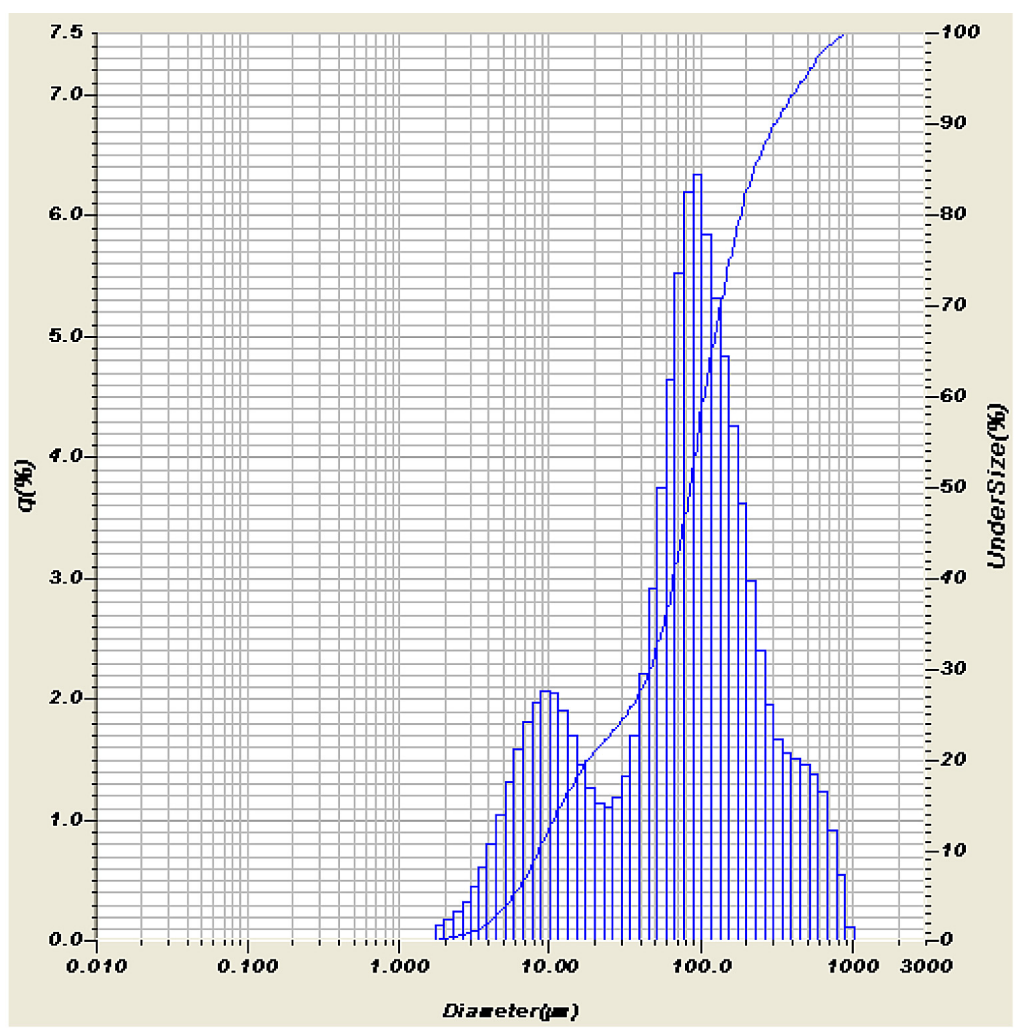

Figure 2. Distribution of particle size wastes in tailing dump "Kovdor MPE" obtained using the analyzer HORIBA LA 950

Rising from the surface of technogenic arrays, the amount of dust is based on the following main factors: wind speed, humidity of the upper layer and the fractional composition. The dependence of the specific volume of dust removal from the tailings humidity and the air flow are shown in Figure 3. Specific volume of dust removal from the surface of the tailings determined in laboratory conditions in a wind tunnel [Mikhailov et al. 1981]. Research findings have shown that at a flow rate of $5 \mathrm{~m} / \mathrm{s}$ and a humidity of more than $6 \%$ tails, blowing dust from the sample surface slightly.

The various fractions are characterized by different transfer distance whose range is expressed in the dependence in Figure 4.

Based on the comparison performed by the specific volume of dust removal and dust transfer distance it can be concluded that the composition of the particulate dust carried in the residential area of Kovdor preferably contains particles of size up to 50 microns, which is due to the close proximity of the tailings $(2.8 \mathrm{~km})$.

Based on a comparison of dispersed compositions tails similar in composition tailing dumps in Russia (Mikhailovsky MPE and Apatit enterprise) it can be concluded that in the beach area of

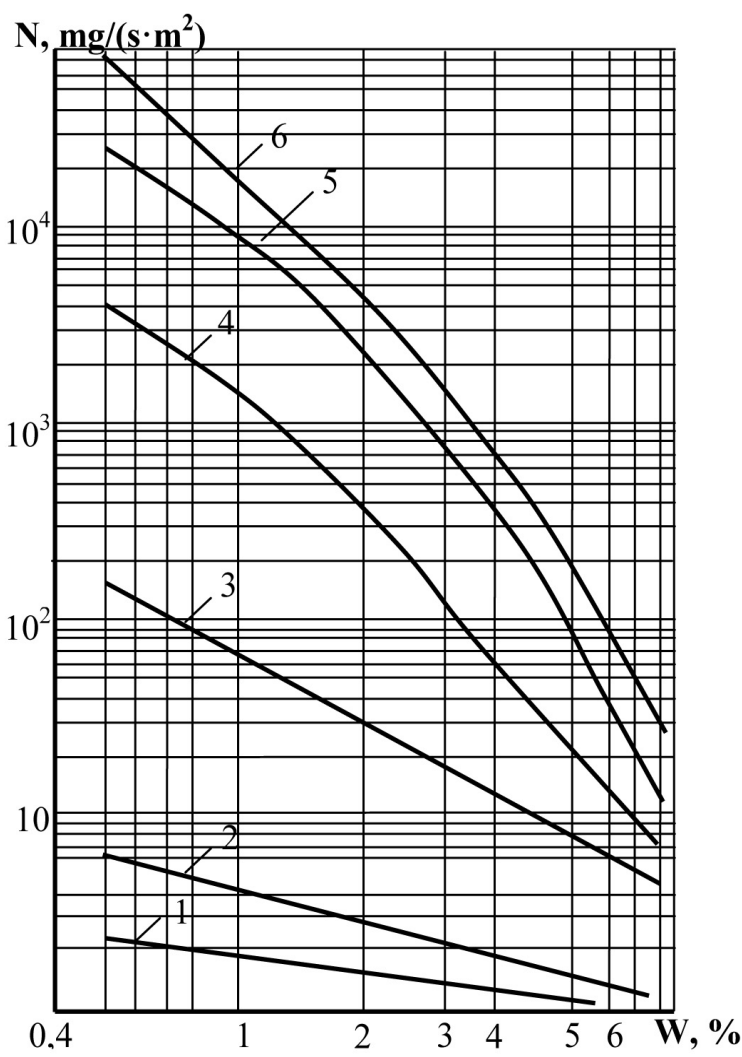

Figure 3. Dependence of Specific volume of dust removal $\mathrm{N}$ tailings humidity $\mathrm{W}$ and air flow rate $\mathrm{v}$ : $1-2 \mathrm{~m} / \mathrm{s}, 2-3.4 \mathrm{~m} / \mathrm{s}, 3-5.1 \mathrm{~m} / \mathrm{s}, 4-6,5 \mathrm{~m} / \mathrm{s}, 5-7.7$ $\mathrm{m} / \mathrm{s}, 6-8.8 \mathrm{~m} / \mathrm{s}$ [Mikhailov et al. 1981] 


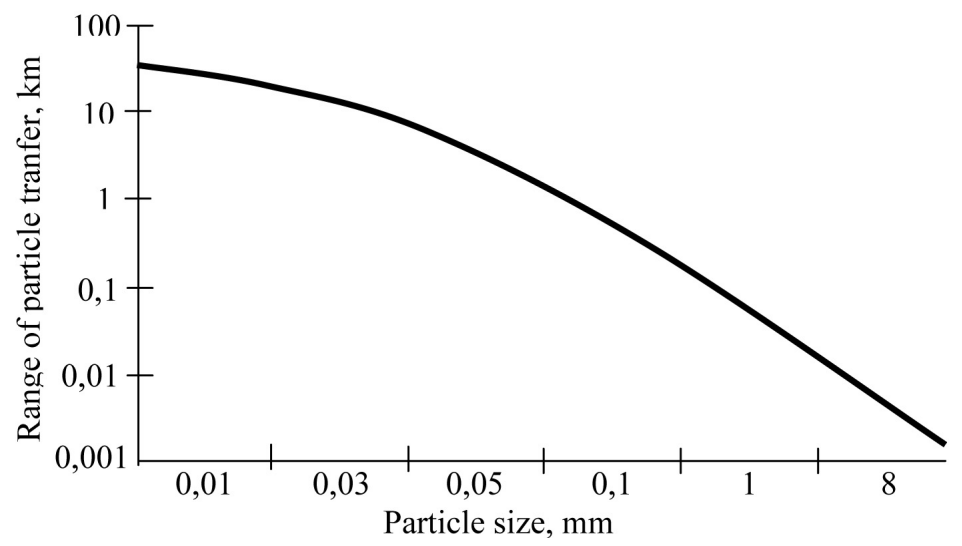

Figure 4. Dependence between the particle diameter and the transfer distance [Ilchenkova 2005]

the Kovdor dump share of dust transferred to the territory of settlements ranged from 10 to $40 \%$. It may be noted that the fine dust fractions are raised to a greater height than the larger fraction.

When using a humidifying system, this can be taken into account in dust suppression sprayers engineering with simulation conditions for certain degree of liquid dispersion [Ivanov et al. 2013, Smirnov et al. 2014].

When atmospheric precipitation in a positive air temperature is moistened, dusting surface layer of the storable component, water absorption and accumulation. The depth depends on the amount of moisture precipitated moisture. The value of the rate of evaporation of rainfall for the region is low, due to the relatively low value of specific irradiance and air temperature on cloudy days. Even in the case of passing the minimum intensity of precipitation when moisture droplets prone surface is dry patches, dusting is not fixed. This is due to the fact that the transfer of a certain amount of dust raised from these areas, is compensated by natural dust suppression (high humidity of air).

In periods with negative air temperature, precipitation before wetted surface is solidified by freezing. In case of snowfall and the formation of steady snow the only place theat is not covered with snow is only the alluvium area, due to the fact that in this area there is a regular movement of pulp, which washes and mixes with a snow on the surface.

Alluvium area is characterized that the movement of pulp is uneven on the surface, the speed of movement in different areas may vary depending on the relative height difference reclamation on particular sites. Direction and "channel" of the pulp will change within the reclamation area. So often in winter because of the frequent snowfalls there are open only "channel", dust emission from which does not occur due to the high humidity in their tailings. Pulp does not reach the critical humidity of $10 \%$, the characteristic to start dust emission, and for the negative impact of temperature and solidifies. From this, it can be concluded that dust emission in the surface of the tailings in winter time does not occur, therefore, the application of measures against dust during this period is not required.

Practically, the analysis of these climatic factors can be made in real time, which allows to quickly model the dust transfer and expeditious measures for dust suppression [Ivanov et al. 2012]. According to the duration of the permanent snow cover and the total number of days with precipitation in the remaining period, we can say that the number of days in a year when possible dust emission and dust transfer in the direction of the city is $15-30$.

That is a big part of the summer period the existing regime of alternate alluvium provides sufficient wetting of the surface of the array.

\section{CONCLUSIONS}

Based on the results of the research, we can conclude that under the conditions of the object, the development of special devices for dust suppression is required. Moreover, the application of isolation methods of dusting the surface is not economically feasible due to continual updating and the expansion of the array dusting surface. One of the possible directions of development of the new devices should be sufficient to maintain surface moisture or precipitation rising dust in the air. There was found that the maximum diameter of the particles carried by the territory of the city 
under consideration is 50 microns. Therefore, when a significant amount of dust emission at the tailings release, the actual amount of dust carried over the city can be much smaller, according to the particle size distribution of the tailings.

\section{REFERENCES}

1. Ilchenkova S. 2005. Reduced dust load on the environment by binding particulate materials dusty surfaces in the territory of mining enterprises. $\mathrm{PhD}$ thesis, pp. 213.

2. Ivanov A., Smirnov Y. 2013. Investigation of the processes of fragmentation of liquid during opera- tion of irrigation systems. Proceedings of the universities. Mining Journal, 3, 32-39.

3. Ivanov A., Smirnov Y. 2012. Development of the automated control system for dust suppression enterprises mineral complex. News TSU. Earth Sciences, Vol. 2, 68-72.

4. Kozlowsky E. Mining Encyclopedia. 5 volumes, 1984-1991, pp. 2900.

5. Mikhailov V., Beresnevich P., Borisov V., Loboda A. 1981. Dust control in ore quarries, pp. 262.

6. Smirnov Y., Ivanov A., Korelsky D. 2014. Simulation of the crushing/agglomeration drops for approach and development of dust control systems devices. International Journal of Ecology \& Development 28(2), 9-17. 